\title{
SOEP
}

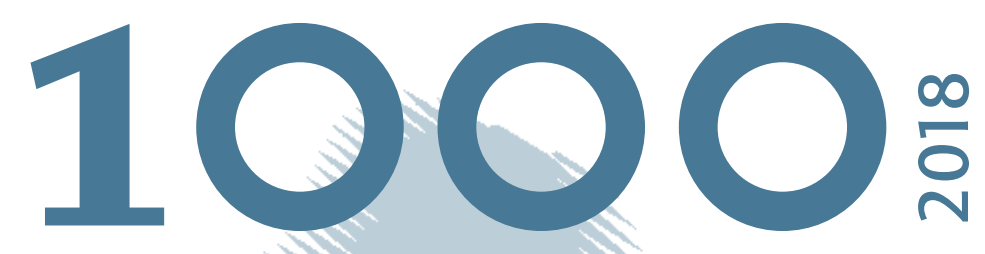

SOEPpapers

on Multidisciplinary Panel Data Research

\section{How Do Households Allocate Risk?}

Christoph Engel, Alexandra Fedorets, Olga Gorelkina 
This series presents research findings based either directly on data from the German SocioEconomic Panel study (SOEP) or using SOEP data as part of an internationally comparable data set (e.g. CNEF, ECHP, LIS, LWS, CHER/PACO). SOEP is a truly multidisciplinary household panel study covering a wide range of social and behavioral sciences: economics, sociology, psychology, survey methodology, econometrics and applied statistics, educational science, political science, public health, behavioral genetics, demography, geography, and sport science.

The decision to publish a submission in SOEPpapers is made by a board of editors chosen by the DIW Berlin to represent the wide range of disciplines covered by SOEP. There is no external referee process and papers are either accepted or rejected without revision. Papers appear in this series as works in progress and may also appear elsewhere. They often represent preliminary studies and are circulated to encourage discussion. Citation of such a paper should account for its provisional character. A revised version may be requested from the author directly.

Any opinions expressed in this series are those of the author(s) and not those of DIW Berlin. Research disseminated by DIW Berlin may include views on public policy issues, but the institute itself takes no institutional policy positions.

The SOEPpapers are available at http://www.diw.de/soeppapers

\section{Editors:}

Jan Goebel (Spatial Economics)

Stefan Liebig (Sociology)

David Richter (Psychology)

Carsten Schröder (Public Economics)

Jürgen Schupp (Sociology)

Conchita D'Ambrosio (Public Economics, DIW Research Fellow)

Denis Gerstorf (Psychology, DIW Research Fellow)

Elke Holst (Gender Studies, DIW Research Director)

Martin Kroh (Political Science, Survey Methodology)

Jörg-Peter Schräpler (Survey Methodology, DIW Research Fellow)

Thomas Siedler (Empirical Economics, DIW Research Fellow)

C. Katharina Spieß (Education and Family Economics)

Gert G. Wagner (Social Sciences)

ISSN: 1864-6689 (online)

German Socio-Economic Panel (SOEP)

DIW Berlin

Mohrenstrasse 58

10117 Berlin, Germany

Contact: soeppapers@diw.de

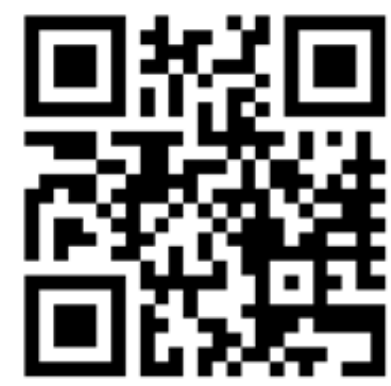




\title{
How Do Households Allocate Risk?*
}

\author{
Christoph Engel, Alexandra Fedorets \& Olga Gorelkina
}

This version: December 2, 2018

\begin{abstract}
Individuals often have to decide to which degree of risk they want to expose others, or how much risk to accept if their choice has an externality on third parties. One typical application is a household. We run an experiment in the German Socio-Economic Panel with two members from 494 households. Participants have a good estimate of each other's risk preferences, even if not explicitly informed. They do not simply match this preference when deciding on behalf of the other household member, but shy away from exposing others to risk. We model the situation, and we find four distinct types of individuals, and two distinct types of households.
\end{abstract}

Keywords: risk preference, household, reticence to expose others to risk, tradeoff between individual and foreign risk preference

JEL Classification: C45, D13, D81, D91

*Helpful comments by Maja Adena, Rida Laraki and Eugenio Verrina are gratefully acknowledged. 


\section{Introduction}

Most individuals are sensitive to risk. They are not indifferent between a lottery and its certainty equivalent (see only Holt and Laury, 2002). Yet in the field, most risk related choices are not taken by individuals deciding in isolation. Many such decisions either directly affect the entire household. Or other household members have a relevant influence on decisions that ultimately only affect a single member. Households decide whether to marry, whether to have children, where to live, how to share bread winning and child rearing, and more mundane choices like the type of car, the destination of the family vacation, or the insurance package. When an adolescent decides which school to attend, which job to choose, maybe also which partner to marry, often her parents weigh in. And her parents will frequently also impact on her choice of lifestyle, her online activities, and her consumption patterns. While the embeddedness of risky choice in households (Granovetter, 1985) is thus hard to deny, it is notoriously difficult to study empirically (for the reasons see Engel, 2010).

We exploit the precious opportunity to introduce an experimental manipulation into a subsample of the German Socio Economic Panel SOEP (Goebel et al., 2018). In the spirit of Eckel and Grossman (2008), we have participants choose one of 11 lotteries. The first lottery is risk free. Participants receive $10 €$ with certainty. In the remaining lotteries, participants put increasing amounts of money at risk. With $50 \%$ probability this money is lost. But with counterprobability of also $50 \%$, the invested amount is doubled up. Hence participants face a gamble between loosing $x$ and gaining $2 * x$, where $x$ is the amount put at risk. They can earn as much as $30 €$. As investment is profitable, a risk neutral participant would choose the riskiest lottery.

We have a within and a between subjects manipulation. Each participant first decides on her own. Subsequently, using the strategy method (Selten, 1967), each participant decides in four situations that affect a second, randomly selected member of the same household: (1) one participant decides on behalf of the other (ruler); (2) one participant decides on behalf of herself and the other (dictator); (3) both household members are exposed to the lottery that is the mean of their individual choices (compromise); (4) both household members are exposed to the lottery that is the less risky of their individual choices (veto). Between subjects before they make the second series of four choices, participants learn, or not, which lottery their partner has chosen in the first part of the experiment, i.e. when deciding on her own.

We propose a theoretical framework that defines the combined effects of three motives: (a) respect for the known or estimated risk preference of the partner; (b) reticence to expose the partner to risk; (c) the tradeoff between the decision maker's own risk 
preference and respect for risk borne by their partner. We also define equilibria for the compromise and veto situations.

Participants are more cautious when deciding as a ruler than when on their own. They are not more cautious when their partner's risk preference is revealed. They are influenced by information about their partner's risk preference, but the effect is only weak. Their main motive is not respect for their partner's preference. Rather they shy away from being responsible for a bad outcome. In line with this finding, participants take more risk when deciding as dictator than when deciding as ruler: they trade off the responsibility effect and the desire to make a higher profit themselves. When each choice carries the same weight (compromise), participants are as cautious as they are as rulers. By contrast if each household member can veto a more risky choice, they behave as when they are dictators. This result fits the responsibility explanation: in veto a risk averse household member can protect herself.

Our theoretical framework enables us to precisely measure the degree by which participants are averse to risk, shy away from responsibility for bad outcomes, and trade this effect off against personal profit. We can exploit the richness of the SOEP to relate these measures to demographic variables. If they have a higher income, or if they are older, participants are less risk averse. If they live in a stable partnership, they are more averse to risk. The responsibility effect is more pronounced in those with higher income, and in females. Those with a job, and the older ones, are less inclined to reduce responsibility when this would reduce their own profit.

Risk attitudes in the household are not only heterogeneous. They can also be clustered. We find four characteristic types. A first type is highly risk averse themselves, and shows little deference to the less pronounced risk aversion of others. This type frequently finds itself in the household with another person, of a second type, who is not particularly risk averse, but highly sensitive to responsibility, and not prone to trading responsibility off for profit. The two remaining types are also frequently together in the same household. The first type is least sensitive to risk themselves, responsible, and hardly prone to reducing responsibility when this reduces her own profit. They are frequently paired with a second person who is more responsible, but only as long as this does not affect her own profit.

The remainder of this paper is organized as follows: section 2 relates the paper to the literature. Section 3 presents the design of the experiment. Section 4 introduces the theoretical framework and develops hypotheses. Section 5 describes the dataset. Section 6 reports results. Section 7 concludes with discussion. 


\section{Literature}

One aspect of risky choice embedded in households is relatively easy to study experimentally: one can replace a randomly selected individual by a randomly composed, anonymously interacting group. This has been shown to matter: groups are less prone to cognitive biases; they suffer less from self-control problems; they are more likely to take risk if this choice maximizes profit (Charness and Sutter, 2012); they are less likely to violate first order stochastic dominance (Charness et al., 2007) and are more likely to maximize profit (Baillon et al., 2016). If individual risk preferences in the group are heterogeneous, the individual with the median risk preference tends to have the strongest effect on group decision-making (Ambrus et al., 2015; also see the meta-study by Wildschut et al., 2003). If a representative decides on behalf of an entire group, her choices are more risk averse than when deciding on her own (Wang et al., 2018).

Taking risk on behalf of others has been studied in dictator games. Recipients receive more if it is uncertain whether they deserve help (Fong, 2007; Fong and Oberholzer-Gee, 2011). They receive most if there is a risk that they leave the lab with nothing (Engel and Goerg, 2018). If transfers influence the probability of winning a lottery, dictators give less than in a traditional dictator game (Brock et al., 2013). They also give less if it is uncertain how much the recipient will benefit from the transfer (Cettolin et al., 2017). Eriksen et al. (2017) do not find that, on average, participants take more or less risk when engaging an anonymous other's money than when deciding about their own money, yet variance is pronounced. Andersson et al. (2014) find that participants are less averse to making losses when deciding on behalf of others, rather than putting their own money at risk. Yet the effect does not replicate if the choice matters for both the decision maker and a third party (Füllbrunn and Luhan, 2017, also see Vieider et al., 2016).

Observational data on household choices is available from surveys like the German Socio Economic Panel SOEP. Risky choices can be correlated with indicators for household composition. That way one for instance finds that married individuals take significantly less risk in general (Halek and Eisenhauer, 2001; Dohmen et al., 2011; Necker and Ziegelmeyer, 2016), but take larger mortgages on their houses (Donkers and Van Soest, 1999); that married females take more risk than females who are single parents (Halek and Eisenhauer, 2001; but see Jianakoplos and Bernasek, 2008); that the risk attitudes of couples tend to correlate (Brown et al., 2012; Bacon et al., 2014). But all these findings rely on self reports that may be biased. Explanatory variables have not been randomly assigned. Most importantly, extant research has not addressed our research question: is risk taking affected by knowing that choices impact on other household 
members?

\section{Design}

Our experiment was run in the SOEP-IS, a subsample of the German Socio Economic Panel that is open for supplementary investigations by additional teams of researchers. We report details of the implementation, and of the remaining survey instruments that are available from this sample, in section 5 below. In this section we focus on the experiment.

From each household, two adult members are selected. If only two household members are available, these two household members are tested. Otherwise household members are randomly selected. The experiment consists of two parts. At the outset, participants only know that a second part is to follow, but do not know what this second part will be about. The two household members earn money if a ten sided dice, that is rolled at the very end of the interview, falls on 10. If they earn money, both parts of the experiment are paid out. All feedback from the entire experiment, including payments, is withheld until participants have responded to the complete survey instrument. This design feature makes sure that questions to the survey are not contaminated.

In the first part of the experiment, participants decide on their own. This part is meant to measure their individual risk preference. Participants see a list with 11 lotteries. Each lottery consists of a high and a low outcome. Both outcomes obtain with probability $50 \%$. Outcomes are given by

$$
\begin{aligned}
& x_{\text {low }}=10-q_{i} \\
& x_{\text {high }}=10+2 q_{i}
\end{aligned}
$$

with $q_{i} \in\{0 . .10\}$. They choose their preferred lottery. If the household receives money, one of the two household members receives a payoff from this first part of the experiment while the other household member receives a payoff from the second part of the experiment.

Using the strategy method, in the second part of the experiment each household member takes four choices. We thus have a $2 \times 4$ factorial design, with one between subjects and three within subjects treatments. They cannot communicate with their partner before choosing. At the very end of the interview, the situation is randomly determined that is payoff relevant. If the first or second situation is singled out, another random draw determines which household member has the active role. Participants again see the list 
of the same 11 lotteries. They now pick a lottery for each of the four situations defined in Table 1. If one of situations 2-4 is randomly determined to be payoff relevant, both household members split earnings evenly.

Table 1: Treatments

\begin{tabular}{l|l|l|l|l}
\hline situation & ruler & dictator & compromise & veto \\
\hline \hline who decides? & A & A & A and B & A and B \\
\hline $\begin{array}{l}\text { who is af- } \\
\text { fected? }\end{array}$ & B A and B & A and B & A and B \\
\hline $\begin{array}{l}\text { how is the } \\
\text { outcome de- } \\
\text { termined? }\end{array}$ & A decides & A decides & $\begin{array}{l}\text { mean of A's } \\
\text { and B's deci- } \\
\text { sion }\end{array}$ & $\begin{array}{l}\text { minimum of and B's } \\
\text { decision }\end{array}$ \\
\hline
\end{tabular}

\section{Theoretical Framework and Hypotheses}

There are two participants $A$ and $B$. Let $q_{i}, i \in\{A, B\}$, denote $i$ 's investment decision. $x(q, \xi)$ is the game's payoff that depends on the investment and realization of a random draw $\xi$. The participants' utility functions $u_{i}(x) \equiv u\left(x ; r_{i}\right), i \in\{A, B\}$, are known up to a single parameter $r_{i}$. This parameter $r_{i}$ is a measure of $i$ 's risk-aversion and at the outset is the participant's private information.

\section{Choice with Effect on Ego Only}

In the first part of the experiment, the participant's choice only affects herself (ego). This choice comes from the expected utility maximization program:

$$
\max _{q_{i} \in\{0 . .10\}}\left\{E_{\xi} u\left(x\left(q_{i}, \xi\right), r_{i}\right)\right\} .
$$

The heterogeneity of solutions to the problem above is due to heterogeneity of participants' aversion to risk.

\section{Choices with Effect on Alter}

In the transparency setting participant $i$ learns her partner's choice $q_{j}$ and hence her level of risk-aversion $r_{j}$. In the intransparency setting the participant works with her 
estimate of the partner's level of risk-aversion $\hat{r}_{j}{ }^{1}$

\section{Ruler}

Participant $i$ takes a decision that will exclusively affect the other participant's (alter's) payoff. If she maximizes her own payoff, she is indifferent. If she minimally cares about $j^{\prime} s$ payoff or utility, she breaks the indifference by making the choice that reflects $j^{\prime} s$ known or estimated degree of risk aversion $r_{j}$ and solves

$$
\max _{q_{i} \in\{0 . .10\}}\left\{E_{\xi} u\left(x\left(q_{i}, \xi\right), r_{j}\right)\right\} .
$$

This gives us

\section{Hypothesis 1. respect for alter's risk preference}

As rulers, participants match the choice alter has made in the first part of the experiment $\left(q_{j}\right)$. The effect is more pronounced if ego receives explicit information about alter's choice when alone.

Yet arguably exposing yourself to risk, and being forced by a third party to bear risk, are not the same. If participants are sensitive to this difference, they might shy away from being responsible for the realization of a particularly bad outcome. Formally participant $i$ might attribute a higher weight to a bad outcome that she imposes on $j$. This would lead her to maximize the partner's utility in expectation over a subjective distribution function, different from the true one. We denote the expectation operator associated with subjective probability weighting $\hat{E}_{\xi}^{i}$. Operator $\hat{E}_{\xi}^{i}$ applied to a random function $g(\xi)$ is defined as

$$
\hat{E}_{\xi}^{i} g(\xi)=\hat{p}_{i} g(L)+\left(1-\hat{p}_{i}\right) g(H)
$$

where $\hat{p}_{i}$ is the weight $A$ puts on the bad outcome $L$, rather than the good outcome $H$ when her choice affects alter's payoff. (3) replaces $E($.$) in (2).$

This gives us our alternative hypothesis

\section{Hypothesis 2. responsibility for a bad outcome}

As rulers, participants choose a lottery that is less risky than the (observed or estimated) choice alter has made in the first part of the experiment $\left(q_{j}\right)$.

\footnotetext{
${ }^{1}$ For simplicity, in the following we use $r_{j}$. All results go through when replacing $r_{j}$ with $\hat{r}_{j}$.
} 


\section{Dictator}

In the role of dictator participant $i$ takes the decision to invest in a joint lottery, the proceeds from which will be split equally between both agents. In this case, participant $i$ solves

$$
\max _{q_{i} \in\{0 . .10\}}\left\{E_{\xi} \mu_{i} u\left(x\left(q_{i}, \xi\right) / 2, r_{i}\right)+\hat{E}_{\xi}^{i}\left(1-\mu_{i}\right) u\left(x\left(q_{i}, \xi\right) / 2, r_{j}\right)\right\},
$$

where $\mu_{i} \in[0,1]$ is the weight that participant $i$ attaches to her own utility. If preferences display constant relative risk aversion, then the preference over lotteries does not change when payoffs are split. Therefore, the subject's choice as a dictator must lie between his choice on her own and as a ruler. This gives us

\section{Hypothesis 3. tradeoff between ego's and alter's utility}

As dictators, participants choose a lottery that is closer to their own risk preference $r_{i}$ than as rulers.

It depends on $r_{j}$ and $\hat{p}_{i}$ whether this choice (a) is more or less risky than the choice made as a ruler, and (b) more or less risky than the choice the participant has made when this only affected her own payoff.

\section{Compromise}

In the compromise case, both participants' decisions are averaged, and the proceeds from the lottery are equally split. For participant $i$, the problem looks as follows:

$$
\max _{q_{i} \in\{0 . .10\}}\left\{E_{\xi} \mu_{i} u\left(x\left(\frac{q_{i}+q_{j}}{2}, \xi\right) / 2, r_{i}\right)+\hat{E}_{\xi}^{i}\left(1-\mu_{i}\right) u\left(x\left(\frac{q_{i}+q_{j}}{2}, \xi\right) / 2, r_{j}\right)\right\} .
$$

The change in the participant's choice between problems (4) and (5) reflects on her expectation of her partner's behavior when she solves the same problem (5). ${ }^{2}$ If $i$ expects her partner to make an investment lower than $i$ 's choice in (4), then $i$ will compensate it by investing more. In the other direction, if the partner's choice is expected to be higher, then $i$ will diminish her investment compared to (4).

If both participants are perfectly prevoyant, they anticipate and try to counteract this compensation. The game has multiple equilibria, with corresponding degrees of compensation. As participants decide simultaneously, and cannot communicate, there is

\footnotetext{
${ }^{2}$ To obtain the partner's problem, interchange indices $i$ and $j$ in (5).
} 
a risk of coordination failure. If $\hat{p}_{i}=.5, \mu_{i}=1$, the participant only cares about her own outcome. In the transparency condition, dictator choices $q_{i}^{*}, q_{j}^{*}$ can be inferred. In the nontransparency condition, the participant can work with her belief $E\left(q_{-k}^{*}\right)$. If $q_{i}^{*}<q_{j}^{*}, j$ would counteract any attempt by $i$ to misrepresent her risk preference and set $\hat{q}_{i}=q_{i}^{*} \pm x_{i}$ by choosing $\hat{q}_{j}=q_{j}^{*} \mp x_{j} . \bar{q}$ remains unchanged as long as both choose the same $x$. Now the action space is constrained to $\hat{q}_{k} \in[0,10]$. If $q_{i}^{*}<5, q_{j}^{*}>5$ the constraint binds for both household members, so that $\bar{q}=5$. Yet if $q_{i}^{*}<5, q_{j}^{*}<5, q_{i}^{*}<q_{j}^{*}$ or if $q_{i}^{*}>5, q_{j}^{*}>5, q_{i}^{*}>q_{j}^{*}$, the constraint only binds for $i$. The equilibrium outcome is $\bar{q}^{*}=\hat{q}_{j}$ in both cases implying that $j$ gets her preferred choice. There are still multiple equilibria.

This gives us

\section{Hypothesis 4. strategic interaction}

a If $q_{i}^{*} \neq q_{j}^{*}$ and $q_{i}^{*}<5, q_{j}^{*}>5$, in the compromise situation, participants choose $\hat{q}_{i}, \hat{q}_{j}$ such that $\frac{\hat{q}_{i}+\hat{q}_{j}}{2}=5$.

$b$ If $q_{i}^{*} \neq q_{j}^{*}, q_{i}^{*}<5, q_{j}^{*}<5$ and $q_{i}^{*}<q_{j}^{*}$, in the compromise situation, participants choose $\hat{q}_{i}, \hat{q}_{j}$ such that $\frac{\hat{q}_{i}+\hat{q}_{j}}{2}=q_{j}^{*}$.

c If $q_{i}^{*} \neq q_{j}^{*}, q_{i}^{*}>5, q_{j}^{*}>5$ and $q_{i}^{*}>q_{j}^{*}$, in the compromise situation, participants choose $\hat{q}_{i}, \hat{q}_{j}$ such that $\frac{\hat{q}_{i}+\hat{q}_{j}}{2}=q_{j}^{*}$.

\section{Veto}

Veto is the same as compromise, except that the effective decision is the minimum of both participants' decisions, and not the average thereof. Participant $i$ solves

$$
\max _{q_{i} \in\{0 . .10\}}\left\{E_{\xi} \mu_{i} u\left(x\left(\min \left\{q_{i}, q_{j}\right\}, \xi\right) / 2, r_{i}\right)+\hat{E}_{\xi}^{i}\left(1-\mu_{i}\right) u\left(x\left(\min \left\{q_{i}, q_{j}\right\}, \xi\right) / 2, r_{j}\right)\right\} .
$$

Similar to the previous case, we can compare the choice in problem (6) with (4). From her choice in (4), we know the participant's preferred level of investment when the proceeds are shared. In veto participant $i$ can guarantee that the investment will not exceed a set level. Thus choosing less than (4) is a dominated strategy. Choosing $q_{i}>q_{i}^{*}$ is dominated as well. Exaggerating $q_{i}$ can only hurt the participant (if $q_{j}>q_{i}$ ) or is immaterial (if $q_{i}>q_{j}$ ). If both participants are fully prevoyant, they tell the truth. This gives us 


\section{Hypothesis 5. truth telling}

In the veto situation, participants choose the same $q_{i}$ as when deciding on behalf of themselves only.

\section{Data}

The experiment is based on the Socio-Economic Panel Innovation Sample (SOEP-IS 2016), which is an extension of the renowned longitudinal survey Socio-Economic Panel (SOEP). ${ }^{3}$ The requirements on the sampling are same as for the SOEP, including representativeness both of cross sections as well as longitudinal perspectives. The SOEP-IS was launched in 2012 to conduct pre-tests of new survey instruments, variables and it also allows to conduct experiments. All proposed survey questions and experiments undergo both an implementation check as well as a quality assessment and ethical clearance by an independent expert and the SOEP Survey Committee. The current study was run with the 2016 wave.

Our experiment involves all avaliable households with two or more members aged above 12, which was our only eligibility criterion. 494 households (988 individuals) participated in our experiment. ${ }^{4}$ To 474 participants $(47.98 \%)$ the choice of their counterpart in the first part of the experiment was revealed before they made choices in the second part of the experiment. Table 2 collects variables that characterize sample characteristics.

\section{Results}

Table 3 shows that all treatments lead to convergence. While choices diverge widely when participants decide on their own, their choices are much more similar when their own choice matters for their counterpart. On average in all treatments, choices of the less and of the more risk averse household member are almost identical. Descriptively choices are less risk averse in the dictator and veto treatments than in the ruler and compromise treatments. In the next sections we look at treatments more closely, and report statistical tests of our hypotheses.

\footnotetext{
${ }^{3}$ More details on SOEP-IS can be found here: https: //www.diw.de/documents/publikationen/73/diw_01.c.407141.de/diw_sp0463.pdf.

${ }^{4}$ We loose three households because one member did not participate in the part of the survey that collects personality related information, the $\mathrm{P}$ questionnaire as the SOEP calls it.
} 
Table 2: Sample Characteristics

\begin{tabular}{l|llllll}
\hline & $\mathrm{N}$ & mean & median & $\min$ & $\max$ & $\mathrm{sd}$ \\
\hline \hline female & 988 & .502 & 1 & 0 & 1 & .500 \\
partnership & 988 & .772 & 1 & 0 & 1 & .420 \\
duration & 988 & 27.172 & 24 & 0 & 72 & 18.528 \\
children & 988 & .582 & 1 & 0 & 1 & .493 \\
religion & 988 & .640 & 1 & 0 & 1 & .480 \\
age & 988 & 54.270 & 55 & 19 & 97 & 17.219 \\
job & 988 & .584 & 1 & 0 & 1 & .493 \\
net personal income & 988 & 996.919 & 450 & 0 & 10000 & 1255.155 \\
effective working hours & 988 & 20.392 & 15 & 0 & 73 & 20.427 \\
regular employment & 988 & .386 & 0 & 0 & 1 & .487 \\
manager & 988 & .154 & 0 & 0 & 1 & .361 \\
debt & 988 & .253 & 0 & 0 & 1 & .435 \\
not on time with payments & 988 & .047 & 0 & 0 & 1 & .211 \\
elementary school & 891 & .329 & 0 & 0 & 1 & \\
middle school & 891 & .380 & 0 & 0 & 1 & \\
high school & 891 & .291 & 0 & 0 & 1 & \\
\hline
\end{tabular}

Data: SOEP-IS 2016, own calculations.

Notes: the table contains information on the distributions of the following variables: female: dummy that is 1 for females; partnership: dummy that is 1 if person lives in stable partnership; duration: of partnership, in years; children: dummy that is 1 if individual has children; religion: dummy that is 1 if individual declares membership in a religious community; age: in years; job: dummy that is 1 if person has any paid occupation; regular employment: dummy that is 1 if person has a regular paid job; net personal income: in $€$; effective working hours: per week; manager: dummy that is 1 if person has responsibility for other employees; debt: dummy that is 1 if person has taken out credit; not on time with payments: dummy; school variables: smaller $\mathrm{N}$ due to missing information. 
Table 3: Mean Choices per Treatment

\begin{tabular}{lll}
\hline & $\begin{array}{l}\text { choice of the } \\
\text { more risk averse } \\
\text { individual }\end{array}$ & $\begin{array}{l}\text { choice of the } \\
\text { less risk averse } \\
\text { individual }\end{array}$ \\
\hline \hline alone & 3.307 & 7.060 \\
ruler & 4.112 & 4.132 \\
dictator & 4.882 & 4.900 \\
compromise & 4.100 & 4.012 \\
veto & 4.654 & 4.895 \\
\hline
\end{tabular}

Data: SOEP-IS 2016, own calculations.

Notes: Split by comparing choices of household members when deciding alone.

\section{Choices when Alone}

Figure 1 shows that risk preferences in the sample are very unevenly distributed. The modal choice is the midpoint of the distribution of options, $q_{i}=5$. If constant relative risk aversion is the correct functional form of utility, this choice corresponds to $r=.5$. The two other modes are at the minimum (which corresponds to $r=\infty$ ), and the maximum (which corresponds to $r=0$ ).

\section{Ruler}

In our first hypothesis we had expected that, when deciding as rulers, participants would match the known or estimated risk preference of their counterpart. As Figure 2 shows, rulers are indeed influenced by the choice their counterpart has made when alone: a fraction of choices is at or near the $45^{\circ}$ line. Yet the correlation is weak: it is only $.311 .^{5}$

The regression in Table 4 shows that participants who are more risk averse themselves (the reference category) make mildly more risky choices when deciding on behalf of their more risk prone counterpart (main effect of ruler). Yet those participants who are more risk seeking when alone make massively less risky choices when deciding on

\footnotetext{
${ }^{5}$ Members of the same household have a common history which, in a statistical sense, creates dependence. We capture the dependence with a household random effect. As Figure 1 demonstrates, we have many choices at either limit of the support. This is why we estimate Tobit models. With this specification, we find that the risk aversion of the other household member has a coefficient of $-.266, \mathrm{p}$ $=.002$. The more the other household member is averse to risk, the less risky the choice of the ruler.
} 


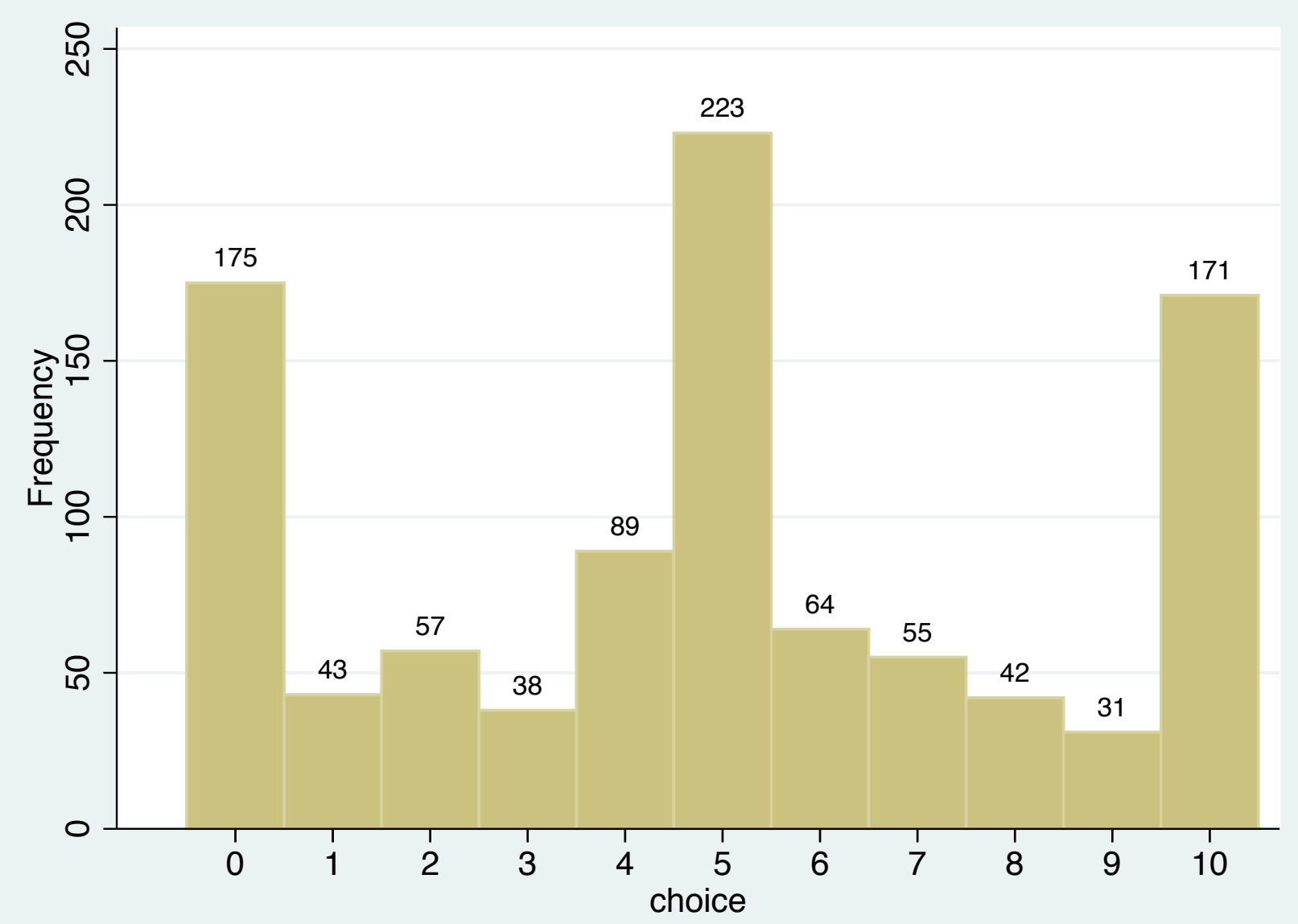

Figure 1: Choice of Lottery when Alone

Data: SOEP-IS 2016, own calculations.

Notes: Frequency of lottery choices when deciding alone. 
behalf of their more risk averse counterpart (interaction between ruler and being more risk prone oneself). The interaction effect almost completely neutralizes the main effect of being more risk prone. This is clear evidence of the responsibility effect. A Wald test shows that the reaction of those household members who have made the more risk prone choice when alone to now being rulers is indeed much stronger. ${ }^{6}$

Table 4: Alone vs. Ruler

\begin{tabular}{ll}
\hline ruler & $1.323^{* * *}$ \\
& $(.204)$ \\
less risk averse household member & $5.629^{* * *}$ \\
& $(.234)$ \\
ruler ${ }^{*}$ less risk averse household member & $-5.313^{* * *}$ \\
& $(.314)$ \\
cons & $2.460^{* * *}$ \\
$\mathrm{~N}$ & $(.204)$ \\
\hline
\end{tabular}

Data: SOEP-IS 2016, own calculations.

Notes: dependent variable: choice of lottery when alone or ruler, Tobit (lower bound 0, upper bound 10). Standard errors for choices nested in individuals nested in households in parentheses.

${ }^{* *} \mathrm{p}<.001,{ }^{* *} \mathrm{p}<.01, * \mathrm{p}<.05$.

As Figure 2 shows, our between subjects manipulation did not have an effect. ${ }^{7}$ This suggests that household members do not need explicit information about the risk preferences of other household members. Living in the same household, they anyway have a good estimate.

We thus support Hypothesis 2 and conclude

\section{Result 1. responsibility effect}

As ruler, the more risk prone household member pays much more deference to the known or estimated risk preference of the other household member than vice versa.

\footnotetext{
${ }^{6}$ Specifically we test ruler - abs(ruler + ruler*less risk averse $)=0, \mathrm{p}<.001$.

${ }^{7}$ If we regress ruler choices on a dummy that is 1 if the counterpart's choice in part 1 of the experiment has been revealed, the counterpart's know or estimated risk preference, and the interaction, the interaction term is insignificant $(\mathrm{p}=.358)$. A treatment effect would have to translate into a significant interaction effect. The additional regression is available from the authors upon request.
} 


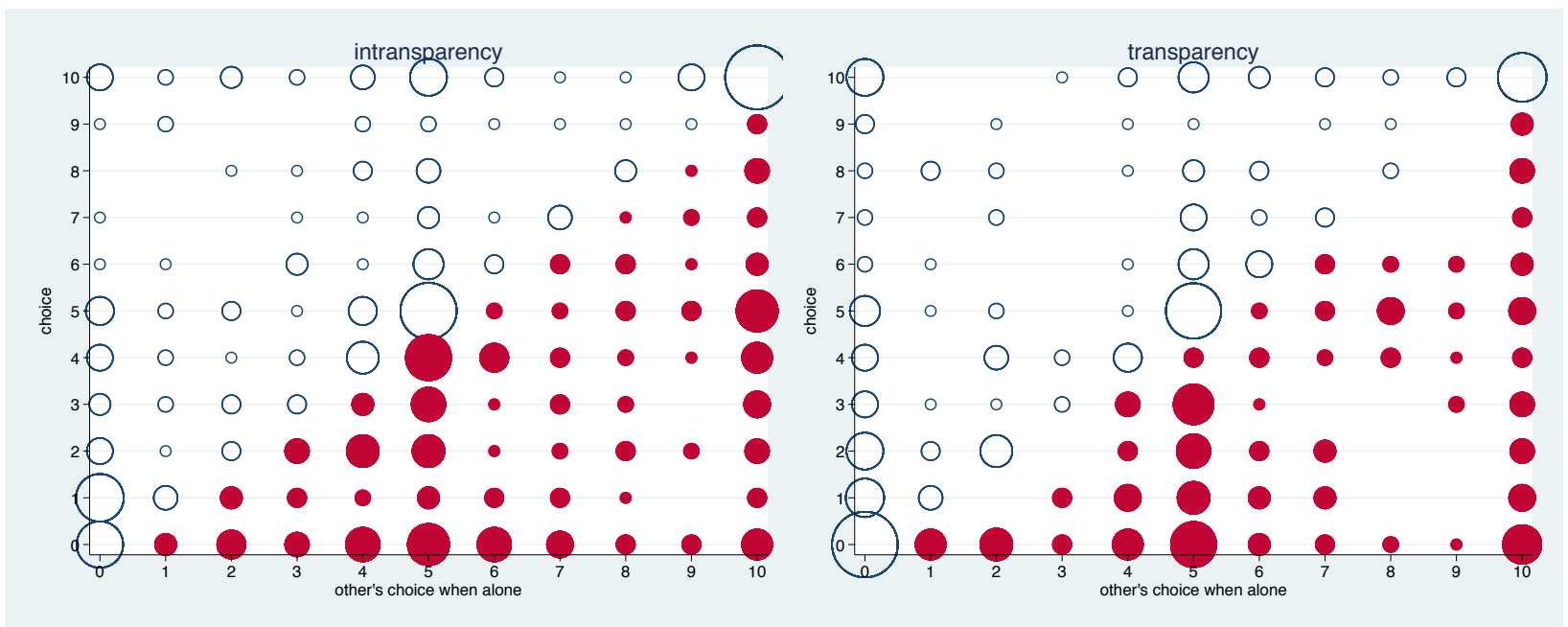

Figure 2: Rulers' Choices

Data: SOEP-IS 2016, own calculations.

Notes: bubble size indicates frequency. Solid bubble: ruler's choice is more risk averse than counterpart's own choice when alone.

\section{Dictator}

In hypothesis 3 we had expected that dictators make choices closer to their own risk preference than as rulers. We test this hypothesis in two steps. In the first step, we check whether dictators make more risky choices overall. The critical piece for the test is, however, the interaction of this main effect with the fact that the participant had been relatively more risk averse than the recipient when deciding on her own. Model 1 in Table 5 compares choices with relevance for the counterpart with the choice the participant has made on her own behalf. ${ }^{8}$ Choices as rulers are substantially and significantly more cautious than individual choices. Yet the effect disappears if participants decide as dictators. ${ }^{9}$

Most importantly in Model 2 the interaction effects with treatments largely neutralize the main effect of being less risk averse: knowing that their choice affects the other household member makes participants more cautious. ${ }^{10}$ Yet the main effect of being a ruler is substantially smaller than the main effect of being a dictator. Risk averse participants take more, not less risk when their choice affects both of them. So effec-

\footnotetext{
${ }^{8}$ We do not control for, or interact with, the transparency manipulation as it remains irrelevant.

${ }^{9} \mathrm{~A}$ Wald test of ruler vs. dictator is significant at $\mathrm{p}<.001$.

${ }^{10}$ Note that, by the design of the regression, the main effects capture the reactions of participants who are more risk averse than their counterparts.
} 
tively both groups of household members take more risk when being dictators. ${ }^{11}$ Only risk prone household members do shift more towards their own risk preferences when deciding as dictator, rather than ruler. Yet this finding has to be read in conjunction with Result 1: as rulers, the more risk prone participants massively move towards the risk preferences of their counterparts. As dictators they partly go back, in the direction of their own risk preference. Hence we do see the effect we had hypothesized, yet it is confined to those participants who show a strong responsibility effect.

We conclude

\section{Result 2. responsibility effect balanced out with own risk preference}

Household members who take more risk than their counterpart when alone take more risk as dictators than as rulers.

\section{Compromise and Veto}

In hypotheses 4 and 5 we had expected strategic action in the compromise, but not in the veto situation. Descriptively we find choices in compromise (mean 4.063) that are very close to the choices made by rulers (mean 4.120), whereas choices in veto (mean 4.756) come very close to the choices made by dictators (mean 4.890), and by participants deciding on their own (mean 4.895).

Strategic interaction in the compromise situation would imply that participants try to exaggerate choices. If they are more risk averse than their counterpart, they should choose a lottery that is even less risky than their actual preference. Conversely if they are less risk averse than their counterpart, they should choose a lottery that is even more risky than their actual preference. As model 1 in Table 6 shows this is clearly not what we observe. The dummy for being less risk averse than the counterpart is significantly negative, not positive, as standard theory would suggest. Instead of strategic interaction, we see a responsibility effect. Participants who are more risk prone themselves anticipate that their choice will inflict more risk on their more cautious counterpart than she wants to bear. By making a more cautious choice themselves they shy away from being responsible for causing bad outcomes. Interestingly we do not see the symmetric pattern for those household members who have been more risk averse in the first place. When alone, these individuals on average chose $q_{i}=3.307$. This is more than the constant of model 1 in Table 6 . The (insignificant) coefficient of the choice

\footnotetext{
${ }^{11}$ Again Wald tests show that these differences in model 2 are significant: more risk averse household members: ruler vs dictator $\mathrm{p}<.001$; less risk averse household members $($ ruler + interaction with being less risk averse) vs. (dictator + interaction with being less risk averse) $\mathrm{p}=.0006$.
} 
Table 5: All Choices

\begin{tabular}{l|ll}
\hline & model 1 & model 2 \\
\hline \hline ruler & $-.972^{* * *}$ & $1.377^{* * *}$ \\
& $(.192)$ & $(.242)$ \\
dictator & .053 & $2.438^{* * *}$ \\
& $(.191)$ & $(.242)$ \\
compromise & $-1.073^{* * *}$ & $1.415^{* * *}$ \\
& $(.191)$ & $(.242)$ \\
veto & -.121 & $2.132^{* * *}$ \\
& $(.191)$ & $(.242)$ \\
less risk averse & & $5.713^{* * *}$ \\
ruler & & $(.270)$ \\
*less risk averse & & $-5.496^{* * *}$ \\
dictator & & $(.372)$ \\
*less risk averse & & $-5.609^{* * *}$ \\
compromise & & $(.372)$ \\
*less risk averse & & $-5.811^{* * *}$ \\
veto & & $(.372)$ \\
*less risk averse & & $-5.298^{* * *}$ \\
cons & $4.878^{* * *}$ & $(.371)$ \\
N & $(.178)$ & $2.449^{* * *}$ \\
\hline
\end{tabular}

Data: SOEP-IS 2016, own calculations.

Notes: dependent variables: choice of lottery (all situations); Tobit (lower bound 0, upper bound 10). Standard errors for choices nested in individuals nested in households in parentheses.

*** $\mathrm{p}<.001,{ }^{* *} \mathrm{p}<.01,{ }^{*} \mathrm{p}<.05$. 
Table 6: Compromise and Veto

\begin{tabular}{l|ll}
\hline & compromise & veto \\
\hline \hline \multirow{2}{*}{ choice when alone } & $.526^{* * *}$ & $.510^{* * *}$ \\
& $(.068)$ & $(.069)$ \\
less risk averse & $-1.220^{*}$ & -.341 \\
& $(.593)$ & $(.638)$ \\
choice when alone & -.142 & $-.185^{+}$ \\
$*$ less risk averse & $(.093)$ & $(.100)$ \\
& $2.223^{* * *}$ & $2.955^{* * *}$ \\
cons & $(.293)$ & $(.297)$ \\
$\mathrm{N}$ & 988 & 988 \\
\hline
\end{tabular}

Data: SOEP-IS 2016, own calculations.

Notes: dependent variable: choice of lottery in compromise and veto situations; Tobit (lower bound 0 , upper bound 10). Standard errors for choices nested in households in parenthesis.

${ }^{* * *} \mathrm{p}<.001,{ }^{* *} \mathrm{p}<.01,{ }^{*} \mathrm{p}<.05,{ }^{+} \mathrm{p}<.1$.

when alone is even negative. Hence we do see a small degree of strategic exaggeration in the choices of the more risk averse of the two household members.

We conclude

\section{Result 3. responsibility in joint decision-making}

If the degree of risk is determined by the mean of both choices, the more risk prone participants make choices that are more cautious than their preferences.

In our theoretical framework we had expected that in the veto situation there would be no exaggerating of risk preferences as this does make no strategic sense. In model 2 of Table 6 we do indeed find a constant that is considerably closer to the mean choice the more risk averse household members have made when deciding on their own. This is a further indicator that the lower constant in model 1 is indeed resulting from strategic exaggeration. Yet in model 2 the coefficient of being the less risk averse household member is also insignificant. This shift from model 1 to model 2 cannot result from strategic considerations; the negative coefficient in model 1 was not strategic in the first place. Rather the more risk prone household members see no reason to protect their counterparts. As anyhow the minimum level of risk is implemented, their counterparts can protect themselves. This interpretation is further supported by comparing the choices of the more risk prone participants across conditions, Table 3 . In veto, these 
household members make about the same choices as they do as dictators (when they must trade their own vs. the other household member's utility), and take considerably more risk than as rulers or in compromise.

We conclude

\section{Result 4. no need for responsibility in veto}

If the degree of risk is determined by the minimum of both choices, participants make choices close to their true preferences.

\section{Parametrization of the Model}

We have a model with three preference parameters. In Appendix B we explain how we parameterize the model. We find that participants are on average mildly risk averse (median $r_{i}=.5$, mean $r_{i}=1.327, \mathrm{sd}=1.776, \min =0, \max =5$ ), sensitive towards being responsible for a bad outcome for their counterpart (median $\hat{p}_{i}=.569$, mean $\left.\hat{p}_{i}=.480, \mathrm{sd}=.229, \min =0, \max =.667\right)$, and put about the same weight on their own and on the risk preference of their counterpart when choices affect both of them (median $\mu_{i}=.431$, mean $\mu_{i}=.488, \mathrm{sd}=.471, \min =0, \max =1$ ). To organize this multidimensional heterogeneity, we use a standard machine learning algorithm. With $\mathrm{k}$-means, we find four distinct types. ${ }^{12}$

154 Type 1 participants are extremely risk averse themselves (mean $q_{i}=0$ ), are hesitant to expose the other household member to risk (mean $\hat{p}_{i}=.600$ ), and do care little about the outcome of their counterpart when their own choice impacts them (mean $\left.\mu_{i}=.712\right)$. Consequently as rulers, they are not very inclined to make more risky choices (mean $q_{i}=1.909$ ). This type makes slightly more risky choices as dictator (mean $q_{i}=3.292$ ) and when choices are defined by the mean of both decisions (mean $q_{i}=2.591$ ). Interestingly when the minimum of both decisions is decisive, choices are substantially more risky (mean $q_{i}=3.636$ ). This suggests that type 1 participants find it more problematic to explicitly override the express will of their counterpart, rather than deviating from her known or estimated risk preference.

All remaining types are not chiefly characterized by their own risk aversion (189 type 2 participants: mean $r_{i}=.992 ; 287$ type 3 participants: mean $r_{i}=.658 ; 358$ type 4 participants: mean $r_{i}=.461$ ), but by the way how they react to treatment. Type 2

\footnotetext{
${ }^{12}$ We standardize all three variables to make sure that they have symmetric impact on the classification. We repeat the procedure 20 times with randomly selected starting points and use majority vote for classification, to make sure that results do not depend on starting points. We use Euclidian distance. Classification is done in $\mathrm{R}$ with the kmeans command.
} 
participants are not concerned about being held responsible for bad outcomes (mean $\left.\hat{p}_{i}=.062\right)$, but balance out the outcome for themselves and for their counterpart when there is a conflict between their own and their counterpart's utility (mean $\mu_{i}=.464$ ). As rulers (mean $q_{i}=6.402$ ) and as dictators (mean $q_{i}=5.534$ ), quite a few of them make fairly risky choices. Their choices are more moderate in the compromise (mean $q_{i}=3.571$ ) and veto settings (mean $q_{i}=4.582$ ); for distributions see Figure 3.

Types 3 and 4 have similar risk preferences (type 3 mean $r_{i}=.658$, type 4 mean $\left.r_{i}=.460\right)$ and almost identical sensitivity towards responsibility for a bad outcome (type 3 mean $\hat{p}_{i}=.594$, type 4 mean $\hat{p}_{i}=.559$ ). Yet they radically differ in the weight they attach to their own outcome. Type 3 puts almost all the weight on her own utility (mean $\mu_{i}=.949$ ), while type 4 puts almost all the weight on her counterpart's utility (mean $\mu_{i}=.037$ ).

Figure 4 shows that types are not randomly distributed across households. There are only 10 households with two extremely risk averse individuals (type $1+$ type 1 pairs). Type 1 individuals are typically together with a second individual that is moderately risk averse herself, but attentive to the extreme risk aversion of her counterpart (48 type $1+$ type 2 pairs). Pairs of two type 3 ( 34 households) or two type 4 participants are more frequent ( 47 households). But type $3+$ type 4 pairs are more prevalent (94 households). Matches of a type 1 or type 2 participant on the one hand with a type 3 or type 4 participant on the other hand are rare. We thus find two distinct types of households. In the first type of household, an extremely risk averse person lives together with another person who is considerate of this extreme preference. In the second type of household, both members are not extremely risk averse, but typically one of them is very sensitive to the well-being of the other, while the other is not.

\section{Heterogeneity and Demographics}

Demographic variables cannot be randomly assigned. One should therefore always be cautious with claiming that demographic features cause effects. Yet as the SOEP provides us with the precious opportunity to check for relationships between our manipulations and demographic variables, in Table 7 we report to which demographic variables the personality characteristics are related that we measure with our experiment.

The left panel reports a linear ${ }^{13}$ multivariate regression ${ }^{14}$ of parameters $r_{i}, \hat{p}_{i}$ and $\mu_{i}$ on a

\footnotetext{
${ }^{13}$ None of the variables is distributed in a way that calls for a different functional form.

${ }^{14}$ Were we to regress each of these variables separately on the set of explanatory variables, we would run into a problem of multiple testing.
} 

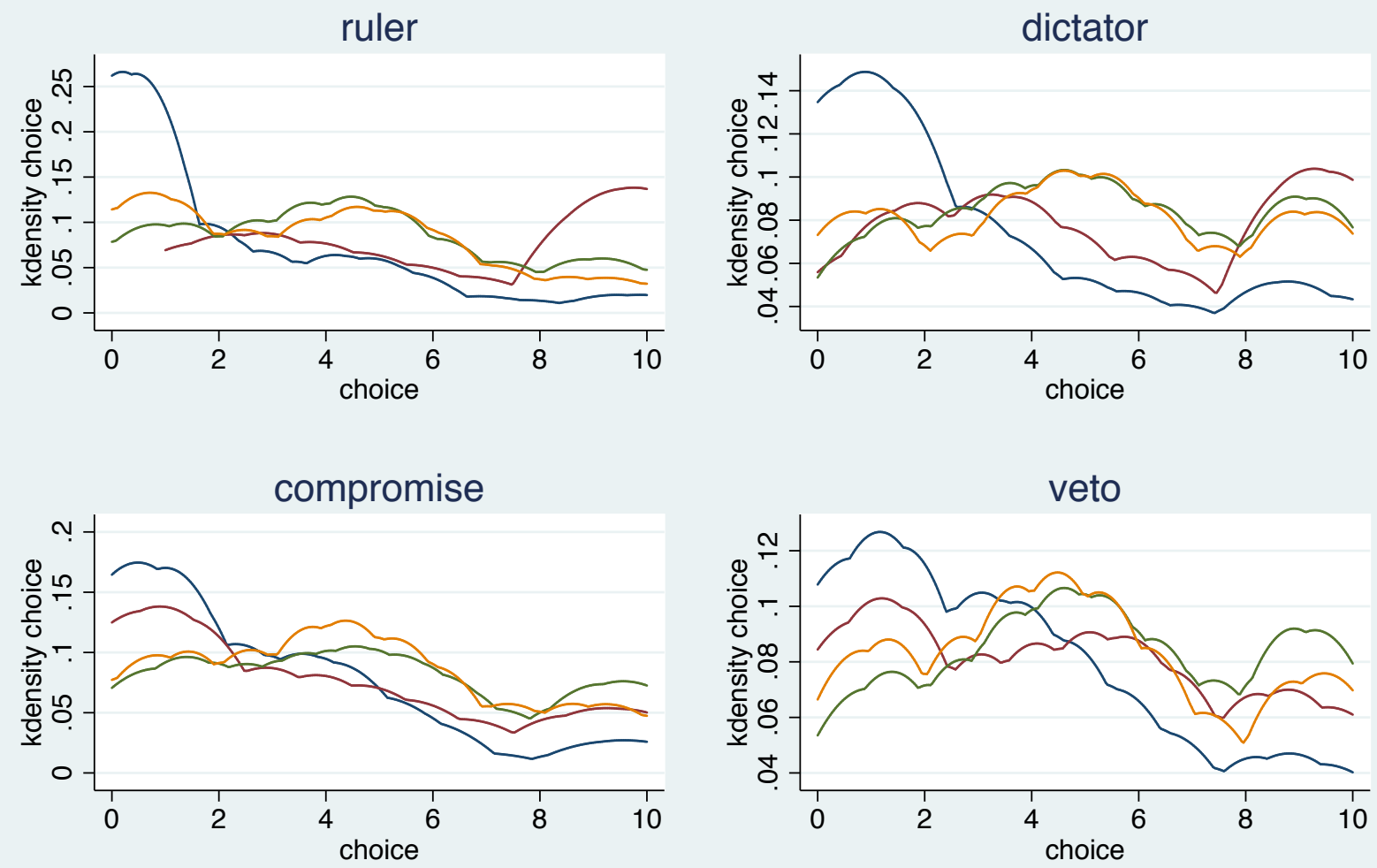

type 1

type 2

type 3

type 4

Figure 3: Choices by Types

Data: SOEP-IS 2016, own calculations.

Notes: Kernel density plots, kernel Epanechnikov.

set of demographic variables that have been elicited in different parts of the interview. ${ }^{15}$ Income has a clear effect. Participants who earn more are less risk averse, and more sensitive towards the risk aversion of their counterpart. Those who have a job put less stress on their personal outcome when outcomes for both household members are at stake. Females are more considerate. Individuals living in a stable partnership are more risk averse. Older participants are more risk averse, and put less stress on their own outcome when it is at stake.

\footnotetext{
${ }^{15}$ The remaining demographic variables listed in Table 2 either have no significant effect on these dependent variables, or they are highly correlated with variables included in the regression. In the latter case we report regressions with the variable that explains most variation.
} 


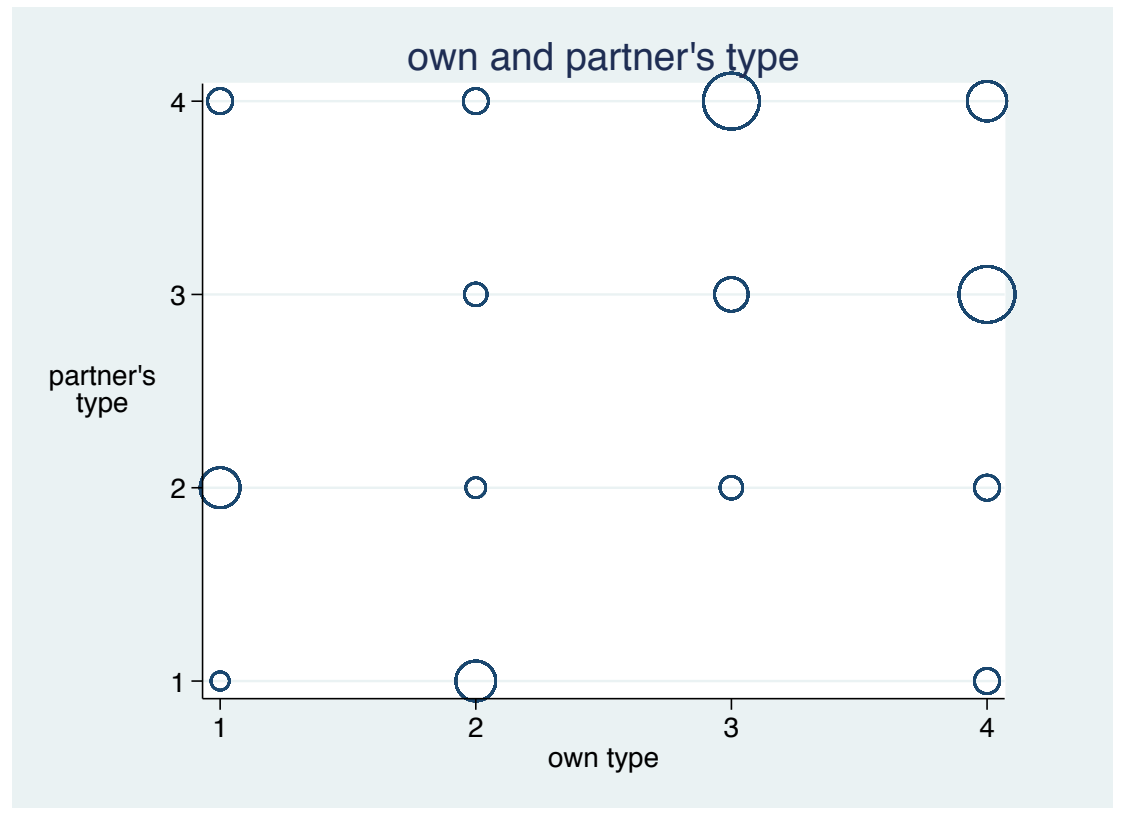

Figure 4: Types by Household

Data: SOEP-IS 2016, own calculations.

Notes: bubble size indicates frequency.

In the right panel of Table 7 , type 1 is the reference category. Positive coefficients thus imply that a participant with the respective demographic characteristic is more likely not to be of type 1 , but of the alternative type in question. Recall that type 1 is composed of participants with extreme risk aversion. The higher the income of a person, the less she is likely to be of this type. ${ }^{16}$ Individuals who live in a stable partnership are most likely to be of type 1, and least likely to be of type 3 . The older a participant, the less she is likely to be of type $1 .{ }^{17}$

\section{Discussion}

In this paper we report on an experiment we have had the precious opportunity to run with a subsample of the German Socio Economic Panel SOEP. Based on a formal theoretical framework, we have tested two members each of 494 households on their

\footnotetext{
${ }^{16}$ Coefficients are practically identical for all three alternative types, so that income is not associated with the tendency to adopt one of the alternative types. For this and all further explanatory variables, please see Table 7 for significance levels.

${ }^{17}$ Again the difference between the propensity to be of one of the alternative types is small.
} 
Table 7: Heterogeneity and Demographics

\begin{tabular}{l|lll|lll}
\hline & \multicolumn{3}{|c|}{ multivariate } & \multicolumn{3}{c}{ multinomial logit } \\
\hline & $r_{i}$ & $\hat{p}_{i}$ & $\mu_{i}$ & type 2 & type 3 & type 4 \\
\hline \multirow{2}{*}{ net income } & $-.0002^{* *}$ & $.00002^{*}$ & .00002 & $.00036^{+}$ & $.00026^{*}$ & $.00024^{+}$ \\
& $(.00006)$ & $(.000008)$ & $(.00002)$ & $(.00014)$ & $(.00012)$ & $(.00012)$ \\
job & -.099 & -.028 & $-.089^{*}$ & .058 & -.021 & .243 \\
& $(.171)$ & $(.023)$ & $(.044)$ & $(.328)$ & $(.310)$ & $(.302)$ \\
female & .048 & $.045^{* *}$ & -.0007 & -.407 & .290 & -.091 \\
& $(.118)$ & $(.016)$ & $(.030)$ & $(.271)$ & $(.198)$ & $(.202)$ \\
partnership & $.345^{*}$ & -.022 & .020 & $-.595^{*}$ & $-.533^{+}$ & $-.517^{+}$ \\
\multirow{4}{*}{ age } & $(.149)$ & $(.020)$ & $(.039)$ & $(.247)$ & $(.309)$ & $(.287)$ \\
& $-.011^{*}$ & .0002 & $-.002^{+}$ & $.016^{*}$ & $.014^{+}$ & $.015^{+}$ \\
cons & $(.004)$ & $(.0006)$ & $(.001)$ & $(.007)$ & $(.008)$ & $(.008)$ \\
$\mathrm{N}$ & $1.844^{* * *}$ & $.502^{* * *}$ & $.655^{* * *}$ & -.389 & -.080 & .139 \\
$\mathrm{~N}$ & $(.281)$ & $(.038)$ & $(.072)$ & $(.466)$ & $(.513)$ & $(.501)$ \\
\hline
\end{tabular}

Data: SOEP-IS 2016, own calculations.

Notes: left panel: dependent variables: see first line; multivariate linear regression, household random effects; right panel: dependent variable: type (as result of cluster analysis); multinomial logit, standard errors clustered at household level, baseoutcome: type 1; variables: net (personal) income: in $€$; job: dummy that is 1 if person has any paid occupation; female: dummy that is 1 for females; partnership: dummy that is 1 if person lives in stable partnership; age: in years;

$* * * \mathrm{p}<.001,{ }^{* *} \mathrm{p}<.01,{ }^{*} \mathrm{p}<.05,{ }^{+} \mathrm{p}<.1$.

attitude towards risk. In the tradition of experimental economics, this test has been fully incentivized. When one household member decides on behalf of the other, they are sensitive towards the other's risk preference. There is no need for them to be explicitly informed about the choice the other household member has made when deciding on her own behalf. It seems that, within a household, individuals have a good sense of others' risk preferences. Yet participants do not simply match the known or estimated risk preference of their passive counterpart. Rather they systematically shift towards less risky choices. They shy away from being responsible for the possibility that risk materialises. When household members decide as dictators, so that their own choice determines the level of risk and opportunity for themselves and their passive counterpart, they shift towards more risky choices. They trade off their own risk preference and the known or estimated risk preference of their counterpart. When the level of risk is determined by the mean of the choices of both household members, choices are again 
more cautious. If, however, in the otherwise identical situation, the minimum choice is decisive, individual choices move closer to their personal preferences.

Using our model, and assuming constant relative risk aversion, for each participant we estimate her degree of risk aversion, the degree by which she shies away from being held responsible for the fact that risk materializes, and the degree by which she privileges her own risk preference over the known or estimated risk preference of her counterpart if her decision matters for both of them. In all three dimensions, heterogeneity is pronounced. This heterogeneity is partly explained by demographic variables (although we do not claim causality in this respect). The most important explanatory variables are income, gender, age, and the fact that a person lives in a stable partnership.

Using a machine learning algorithm, we classify individuals along all three of these preference dimensions into four distinct types. Two observations are particularly noteworthy: a minority of participants are extremely averse to risk, and differ in all characteristics from the remaining participants. These individuals often live together in a household with a second person who is much less averse to risk, but very attentive to the different risk preference of the first person. There are also many households composed of one individual that almost exclusively cares about her own utility, while the other almost exclusively cares about the utility of the other household member.

This composition of the type space stresses the obvious: household membership is not randomly assigned. As adults, partners find themselves. As children, they grow up in households. We therefore cannot claim to have identified the causal effect of household membership on risk-taking. All we can test is the effect of random assignment to treatment on individuals who interact with another member of a pre-existing household. Yet the fact that we had the privilege to run this experiment in the SOEP did not only give us access to a fairly large sample. We knew this sample to be well balanced along multiple demographic dimensions. And we do even have individual information about these characteristics and can use them as explanatory variables. To the extent possible we are therefore confident that we can make a generalisable claim about risk-taking with effect on a second member of a representative German household. 


\section{References}

Attila Ambrus, Ben Greiner, and Parag A Pathak. How individual preferences are aggregated in groups: An experimental study. Journal of Public Economics, 129: $1-13,2015$.

Ola Andersson, Håkan J Holm, Jean-Robert Tyran, and Erik Wengström. Deciding for others reduces loss aversion. Management Science, 62(1):29-36, 2014.

Philomena M Bacon, Anna Conte, and Peter G Moffatt. Assortative mating on risk attitude. Theory and Decision, 77(3):389-401, 2014.

Aurélien Baillon, Han Bleichrodt, Ning Liu, and Peter P Wakker. Group decision rules and group rationality under risk. Journal of Risk and Uncertainty, 52(2):99-116, 2016.

JMichelle Brock, Andreas Lange, and E Ozbay. Dictating the risks: Experimental evidence on norms of giving in risky environments. American Economic Review, 103: 415-4337, 2013.

Sarah Brown, Andrew Dickerson, Jolian McHardy, and Karl Taylor. Gambling and credit: an individual and household level analysis for the uk. Applied Economics, 44 (35):4639-4650, 2012.

Elena Cettolin, Arno Riedl, and Giang Tran. Giving in the face of risk. Journal of Risk and Uncertainty, 55(2-3):95-118, 2017.

Gary Charness and Matthias Sutter. Groups make better self-interested decisions. Journal of Economic Perspectives, 26(3):157-76, 2012.

Gary Charness, Edi Karni, and Dan Levin. Individual and group decision making under risk: An experimental study of bayesian updating and violations of first-order stochastic dominance. Journal of Risk and uncertainty, 35(2):129-148, 2007.

Thomas Dohmen, Armin Falk, David Huffman, Uwe Sunde, Jürgen Schupp, and Gert G Wagner. Individual risk attitudes: Measurement, determinants, and behavioral consequences. Journal of the European Economic Association, 9(3):522-550, 2011.

Bas Donkers and Arthur Van Soest. Subjective measures of household preferences and financial decisions. Journal of Economic Psychology, 20(6):613-642, 1999. 
Catherine C Eckel and Philip J Grossman. Forecasting risk attitudes. an experimental study using actual and forecast gamble choices. Journal of Economic Behavior and Organization, 68(1):1-17, 2008.

Christoph Engel. The behaviour of corporate actors. how much can we learn from the experimental literature? Journal of Institutional Economics, 6:445-475, 2010.

Christoph Engel and Sebastian J Goerg. If the worst comes to the worst: Dictator giving when recipient's endowments are risky. European Economic Review, 105:51-70, 2018.

Kristoffer Wigestrand Eriksen, Ola Kvaloy, and Miguel Luzuriaga. Risk-taking on behalf of others. 2017.

Christina M Fong. Evidence from an experiment on charity to welfare recipients: Reciprocity, altruism and the empathic responsiveness hypothesis. The Economic Journal, 117(522):1008-1024, 2007.

Christina M Fong and Felix Oberholzer-Gee. Truth in giving: Experimental evidence on the welfare effects of informed giving to the poor. Journal of Public Economics, 95(5):436-444, 2011.

Sascha C Füllbrunn and Wolfgang J Luhan. Decision making for others: The case of loss aversion. Economics Letters, 161:154-156, 2017.

Jan Goebel, Markus M. Grabka, Stefan Liebig, Martin Kroh, David Richter, Carsten Schröder, and Jürgen Schupp. The German Socio-Economic Panel (SOEP). Jahrbücher für Nationalökonomie und Statistik/Journal of Economics and Statistics, 0(0):online first, 2018.

Marc Granovetter. Economic action and social structure. the problem of embeddedness. American Journal of Sociology, 91:481-510, 1985.

Martin Halek and Joseph G Eisenhauer. Demography of risk aversion. Journal of Risk and Insurance, 68:1-24, 2001.

Charles A. Holt and Susan K. Laury. Risk aversion and incentive effects. American Economic Review, 92:1644-1655, 2002.

Nancy Ammon Jianakoplos and Alexandra Bernasek. Family financial risk taking when the wife earns more. Journal of Family and Economic Issues, 29(2):289-306, 2008.

Sarah Necker and Michael Ziegelmeyer. Household risk taking after the financial crisis. The Quarterly Review of Economics and Finance, 59:141-160, 2016. 
Reinhard Selten. Die Strategiemethode zur Erforschung des eingeschränkt rationalen Verhaltens im Rahmen eines Oligopolexperiments. In Ernst Sauermann, editor, Beiträge zur experimentellen Wirtschaftsforschung, pages 136-168. Mohr, Tübingen, 1967.

Ferdinand M Vieider, Clara Villegas-Palacio, Peter Martinsson, and Milagros Mejía. Risk taking for oneself and others: A structural model approach. Economic Inquiry, 54(2):879-894, 2016.

Zuo-Jun Wang, Yi Kuang, Hui-Yi Tang, Cong Gao, Ai Chen, and Kai Qin Chan. Are decisions made by group representatives more risk averse? the effect of sense of responsibility. Journal of Behavioral Decision Making, 31(3):311-323, 2018.

Tim Wildschut, Brad Pinter, Jack L Vevea, Chester A Insko, and John Schopler. Beyond the group mind: a quantitative review of the interindividual-intergroup discontinuity effect. Psychological bulletin, 129(5):698, 2003. 


\section{Appendix}

\section{A Instructions}

\section{First Part of the Experiment}

Please tick the lottery you want to chose. You can only tick a single lottery.

\begin{tabular}{|c|c|c|c|}
\hline Nr. of lottery & $\begin{array}{l}\text { event } \\
\text { (probability) }\end{array}$ & payoff & $\begin{array}{l}\text { your chosen } \\
\text { lottery }\end{array}$ \\
\hline \multirow[t]{2}{*}{$\overline{1} 1$} & high $(50 \%)$ & $10 €$ & \\
\hline & low $(50 \%)$ & $10 €$ & \\
\hline \multirow[t]{2}{*}{2} & high $(50 \%)$ & $12 €$ & \\
\hline & low $(50 \%)$ & $9 €$ & \\
\hline \multirow[t]{2}{*}{3} & high $(50 \%)$ & $14 €$ & \\
\hline & low $(50 \%)$ & $8 €$ & \\
\hline \multirow[t]{2}{*}{4} & high $(50 \%)$ & $16 €$ & \\
\hline & low $(50 \%)$ & $7 €$ & \\
\hline \multirow[t]{2}{*}{5} & high $(50 \%)$ & $18 €$ & \\
\hline & low $(50 \%)$ & $6 €$ & \\
\hline \multirow[t]{2}{*}{6} & high (50\%) & $20 €$ & \\
\hline & low $(50 \%)$ & $5 €$ & \\
\hline \multirow[t]{2}{*}{7} & high $(50 \%)$ & $22 €$ & \\
\hline & low $(50 \%)$ & $4 €$ & \\
\hline \multirow[t]{2}{*}{8} & high $(50 \%)$ & $24 €$ & \\
\hline & low $(50 \%)$ & $3 €$ & \\
\hline \multirow[t]{2}{*}{9} & high $(50 \%)$ & $26 €$ & \\
\hline & low $(50 \%)$ & $2 €$ & \\
\hline \multirow[t]{2}{*}{10} & high $(50 \%)$ & $28 €$ & \\
\hline & low $(50 \%)$ & $1 €$ & \\
\hline \multirow[t]{2}{*}{11} & high $(50 \%)$ & $30 €$ & \\
\hline & low $(50 \%)$ & $0 €$ & \\
\hline
\end{tabular}




\section{Second Part of the Experiment}

In this part of the experiment, you are making 4 choices. After you have made your choices, it is randomly determined which of the 4 choices is relevant. Please do therefore take all 4 choices seriously.

In this part of the experiment, the choice you make also matters for the second member of the household who participates in the experiment.

For choices 1 and 2, eventually only the choice of one of the participants is relevant. In the table below we have called this participant A. Who of you has this role is, however, only determined afterwards and randomly. Please do therefore make a choice as if you knew that it is relevant.

The four situations differ in two dimensions: whose choice is relevant (only A's choice, or the choices of both participants?). And for who do these choices matter (only for $\mathrm{B}$, or for $\mathrm{A}$ and $\mathrm{B}$ ?). If eventually the choices matter for $\mathrm{A}$ and $\mathrm{B}$, the four situations differ by the way that the lottery is selected that will be paid out. For detail, please consult the header of the table below.

Please select for each of the four situations one lottery. The Interviewer will have chance decide which situation is relevant, and will play it out.

\section{B Parameterization of the Model}

Closed-form solutions for $r_{i}, \hat{p}_{i}$ and $\mu_{i}$ can be obtained once we fix the utility function form $u_{i}(x) \equiv u\left(x ; r_{i}\right)$. For parameterization, we use CRRA and hence assume

$$
u\left(x ; r_{i}\right)=\frac{1}{1-r_{i}} x^{1-r_{i}}
$$

where $r_{i} \in(0,1)$.

Solving for $r_{i}$. Problem 1 becomes:

$\max _{q_{i} \in\{0 . .10\}}\left\{E_{\xi} u\left(x\left(q_{i}, \xi\right), r_{i}\right)\right\}=\max _{q_{i} \in\{0 . .10\}} \frac{1}{2}\left(\frac{1}{1-r_{i}}\left(10-q_{i}\right)^{1-r_{i}}+\frac{1}{1-r_{i}}\left(10+2 q_{i}\right)^{1-r_{i}}\right)$

The objective function is concave, the first order condition is given by 


\begin{tabular}{|c|c|c|c|c|c|c|}
\hline & \multicolumn{2}{|c|}{$\begin{array}{l}\text { situation } \\
\text { who decides? } \\
\text { who is affected? } \\
\text { how is the outcome } \\
\text { determined? }\end{array}$} & $\begin{array}{l}1 \\
\text { A } \\
\text { B } \\
\text { A's } \\
\text { decision }\end{array}$ & $\begin{array}{l}2 \\
\text { A } \\
\text { A and B } \\
\text { A's } \\
\text { decision }\end{array}$ & $\begin{array}{l}3 \\
\mathrm{~A} \text { and } \mathrm{B} \\
\mathrm{A} \text { and } \mathrm{B} \\
\text { mean }\end{array}$ & $\begin{array}{l}4 \\
A \text { and } B \\
A \text { and } B \\
\text { lowest number } \\
\text { of lottery }\end{array}$ \\
\hline $\begin{array}{l}\text { Nr. of } \\
\text { lottery }\end{array}$ & $\begin{array}{l}\text { event } \\
\text { (probability) }\end{array}$ & payoff & & & & \\
\hline 1 & $\begin{array}{l}\text { high }(50 \%) \\
\text { low }(50 \%)\end{array}$ & $\begin{array}{l}10 € \\
10 €\end{array}$ & & & & \\
\hline 2 & $\begin{array}{l}\text { high }(50 \%) \\
\text { low }(50 \%)\end{array}$ & $\begin{array}{l}12 € \\
9 €\end{array}$ & & & & \\
\hline 3 & $\begin{array}{l}\text { high }(50 \%) \\
\text { low }(50 \%)\end{array}$ & $\begin{array}{l}14 € \\
8 €\end{array}$ & & & & \\
\hline 4 & $\begin{array}{l}\text { high }(50 \%) \\
\text { low }(50 \%)\end{array}$ & $\begin{array}{l}16 € \\
7 €\end{array}$ & & & & \\
\hline 5 & $\begin{array}{l}\text { high }(50 \%) \\
\text { low }(50 \%)\end{array}$ & $\begin{array}{l}18 € \\
6 €\end{array}$ & & & & \\
\hline 6 & $\begin{array}{l}\text { high }(50 \%) \\
\text { low }(50 \%)\end{array}$ & $\begin{array}{l}20 € \\
5 €\end{array}$ & & & & \\
\hline 7 & $\begin{array}{l}\text { high }(50 \%) \\
\text { low }(50 \%)\end{array}$ & $\begin{array}{l}22 € \\
4 €\end{array}$ & & & & \\
\hline 8 & $\begin{array}{l}\text { high }(50 \%) \\
\text { low }(50 \%)\end{array}$ & $\begin{array}{l}24 € \\
3 €\end{array}$ & & & & \\
\hline 9 & $\begin{array}{l}\text { high }(50 \%) \\
\text { low }(50 \%)\end{array}$ & $\begin{array}{l}26 € \\
2 €\end{array}$ & & & & \\
\hline 10 & $\begin{array}{l}\text { high }(50 \%) \\
\text { low }(50 \%)\end{array}$ & $\begin{array}{l}28 € \\
1 €\end{array}$ & & & & \\
\hline 11 & $\begin{array}{l}\text { high }(50 \%) \\
\text { low }(50 \%)\end{array}$ & $\begin{array}{l}30 € \\
0 €\end{array}$ & & & & \\
\hline
\end{tabular}




$$
\left(10-q_{i}\right)^{-r_{i}}=2\left(10+2 q_{i}\right)^{-r_{i}}
$$

which is equivalent to

$$
r_{i} \ln \left(\frac{10+2 q_{i}}{10-q_{i}}\right)=\ln 2 .
$$

Hence, observing investment choice $q_{i}^{1}$ in the first part of the experiment (alone), we can calculate $i$ 's risk aversion coefficient $r_{i}=\ln 2 / \ln \left(\frac{10+2 q_{i}}{10-q_{i}}\right)$. The values of $r_{i}$ for integer $q_{i}^{1}$ 's are given in Table $8 .^{18}$

Table 8: Stage 1 choices and the corresponding relative risk aversion coefficients if utility functions are of CRRA type

\begin{tabular}{cccccccccccc}
\hline$q_{i}^{1}$ & 0 & 1 & 2 & 3 & 4 & 5 & 6 & 7 & 8 & 9 & 10 \\
\hline \hline$r_{i}$ & $+\infty$ & 2.41 & 1.24 & 0.84 & 0.63 & 0.50 & 0.41 & 0.33 & 0.27 & 0.21 & 0 \\
\hline
\end{tabular}

\section{Solving for $\hat{p}_{i}$}

From (3) we have

$$
\hat{p}_{i}\left(10-q_{i}\right)^{-r_{j}}=2\left(1-\hat{p}_{i}\right)\left(10+2 q_{i}\right)^{-r_{j}},
$$

which is equivalent to ${ }^{19}$

$$
\hat{p}_{i}=\frac{2\left(10-q_{i}\right)^{r_{j}}}{2\left(10-q_{i}\right)^{r_{j}}+\left(10+2 q_{i}\right)^{r_{j}}} .
$$

Solving for $\mu_{i}$. With CRRA utility functions, Problem (4) becomes

$$
\max _{q_{i} \in\{0 . .10\}}\left\{E_{\xi}\left[\mu_{i} u\left(x\left(q_{i}, \xi\right) / 2, r_{i}\right)+\left(1-\mu_{i}\right) u\left(x\left(q_{i}, \xi\right) / 2, r_{j}\right)\right]\right\}
$$

\footnotetext{
${ }^{18}$ In order not to loose data from participants who choose $q_{i}^{1}=0$ in estimating $\hat{p}_{i}$ and $\mu_{i}$, in our estimations we set $r_{i}\left(q_{i}^{1}=0\right)$ to 5 .)

${ }^{19}$ With our design, $r_{i}$ can be 0 , and mathematically $0^{q_{i}<1}$ is $\infty$. As $\hat{p}_{i} \in[0,1]$, we map $\hat{p}\left(r_{i}=0, q_{i}<\right.$ 1) $\rightarrow 1$
} 


$$
\begin{gathered}
=\max _{q_{i} \in\{0 . .10\}}\left\{\frac{\mu_{i}}{2}\left(\frac{1}{1-r_{i}}\left(\frac{10-q_{i}}{2}\right)^{1-r_{i}}+\frac{1}{1-r_{i}}\left(\frac{10+2 q_{i}}{2}\right)^{1-r_{i}}\right)\right. \\
\left.+\frac{1-\mu_{i}}{2}\left(\frac{1}{1-r_{j}}\left(\frac{10-q_{i}}{2}\right)^{1-r_{j}}+\frac{1}{1-r_{j}}\left(\frac{10+2 q_{i}}{2}\right)^{1-r_{j}}\right)\right\}
\end{gathered}
$$

The objective function is concave, the first order condition is given by

$$
\frac{\mu_{i}}{2}\left(-\frac{1}{2}\left(5-0.5 q_{i}\right)^{-r_{i}}+\left(5+q_{i}\right)^{-r_{i}}\right)+\frac{1-\mu_{i}}{2}\left(-\frac{1}{2}\left(5-0.5 q_{i}\right)^{-r_{j}}+\left(5+q_{i}\right)^{-r_{j}}\right)=0
$$

which implies

$$
\mu_{i}=\frac{-o_{l}^{-r_{j}}+2 o_{h}^{-r_{j}}}{-o_{l}^{-r_{j}}+2 o_{h}^{-r_{j}}-2 o_{h}^{-r_{i}}+o_{l}^{-r_{i}}}
$$

using $o_{l}:=5-\frac{1}{2} q_{i}$ and $o_{h}:=5+q_{i}{ }^{20}$

\footnotetext{
${ }^{20}$ We again need adjustments to make sure we do not loose data. Mathematically, with $r_{i}>0$, $0^{-r} \in \mathbb{C}$. To keep such datapoints, we use $o_{l}^{-r}=.1$. Mathematically, the denominator of (4) can be 0 . We would loose datapoints as we cannot divide by 0 . In such cases, we set the denominator to 1 . Finally, as our model defines $\mu_{i} \in[0,1]$, we map $\tilde{\mu}_{i}<0 \rightarrow \mu_{i}=0$, and $\tilde{\mu}_{i}>1 \rightarrow \mu_{i}=1$.
} 